\title{
Body, Technology and Society: a Dance of Encounters
}

\author{
Bárbara Nascimento Duarte • Enno Park
}

Received: 24 October 2014 / Accepted: 24 October 2014 /Published online: 2 November 2014

(C) Springer Science+Business Media Dordrecht 2014

\begin{abstract}
In the special section 'Body Hacking: SelfMade Cyborgs and Visions of Transhuman Corporeality', attention is drawn to cyborgism, a set of cultural and very personal practices of experimentation with the human body that often take place outside the confines of institutionalised technoscience. Known, for example, as 'body hackers', 'grinders' or 'self-made cyborgs' and engaging in unusual forms of body modification, the practitioners are enthusiasts who do not necessarily have any 'disability' in the conventional sense of the term. They consider the body a highly malleable material, a transformable, improvable, augmentable entity. The collection of papers in this special section encompasses first-hand accounts of cyborg practices as well as intellectual reflections on their implications.
\end{abstract}

Keywords Cyborg $\cdot$ Human enhancement $\cdot$ Body hacking $\cdot$ Transhumanism

Looking at current developments at the intersections of human corporeality and technology and alluding to Bruno Latour's famous statement 'We have never been

B. N. Duarte $(\square)$

Federal University of Juiz de Fora, Juiz de Fora, Brazil

e-mail: duarte.n.barbara@gmail.com

B. N. Duarte

University of Strasbourg, Strasbourg, Brazil

E. Park

Cyborgs e.V., Berlin, Germany

e-mail: enno.park@cyborgs.cc modern' [1], we may ask if humans have ever been truly 'human'. According to Latour, any material or immaterial entity is potentially an actor due its embedded power to associate and build relations. Such entities act by revealing connections and interactions and by forming organic and inorganic collectives. This does not imply that objects act in place of humans or that they have a similar value to humans. It is an analytical stance, not an ethical position. Like, among others, John Law and Donna Haraway, Latour has demonstrated the power of hybrids to generate unpredictability in vast networks composed of people and objects, which participate in social constructs so diverse that the researcher should not disregard any possible associations between them. It is not a matter of reconciling the subject/object dichotomy, however, but of drawing attention to distributed agency in such networks and to unlikely and unexpected associations, doing so against the backdrop of the artefactuality of nature, and the apparatus of object and bodily production.

This special section, 'Body Hacking: Self-Made Cyborgs and Visions of Transhuman Corporeality', aims to contribute to a better understanding of how agents and 'actants' - this Latourian term having a broader meaning than 'actor', encompassing human and non-human agency-function in the world and relate to each other. As the essays in this special section again show, the interaction of actants takes place in multiple and surprising ways. Donna Haraway [2] argues that every entity, be it organic or inorganic, human or non-human, is entangled in a ceaseless process of assemblage in which all entities are partners, performing intra- and inter-actions. Insofar as they are linked by relationships of 
association, connection and companionship, both subjects and objects shape reality in a 'dance of encounters'. The process of becoming they go through with many others involves more than mere interaction. Haraway prefers the word 'intra-action' in this context, using it to refer to the reciprocal co-definition of components as they emerge together, supporting their own existence and reshaping themselves in relation to one another, thus leading to unpredictable social interactions. Looking at the dance of encounters between human corporeality and technology, we find ourselves confronted with the prospect of a transfiguration of the human species as it moves towards a future that is unknown, although many technoscientific and social imaginaries entail speculation about it.

The vision of a posthumanity is one of these imaginaries. In this context, there has recently been a broad debate about the term 'posthumanism'. While some authors identify it with transhumanism, others, often referring to Continental European traditions of thought from Martin Heidegger to Michel Foucault and Gilles Deleuze, use the term to interrogate the modern focus on the human subject and human agency. We may argue that throughout its history, humankind has always created technology and interacted with it and that technology can be understood as an extension of the human being. Posthumanism then goes beyond this evolutionary stage, not only transforming human capacities and performance, but key features of the human species and its corporeality as well. The posthuman is understood by Katherine Hayles [3] as a hybrid in which the human is closely coupled with intelligent machines. Andy Clark [4] portrays humans as 'natural born cyborgs', arguing that bodies (will) consist of a set of purely utilitarian elements, as potentialities interacting with other largely or fully artificial entities and the environment. Do such views of the posthuman imply that posthumanism departs from the Enlightenment project and thus runs counter to transhumanism, which usually defines itself as the legitimate heir to this project? Transhumanism can be understood as a cultural and intellectual movement that aspires to transcend the human species, which it considers imperfect. The transhumanist dream is to overcome the human condition with the aid of new and emerging fields of technoscience, such as nanotechnology, biotechnology, information technology and cognitive science, and to create not just an 'enhanced' human, but posthuman beings that are free of any constraints, liberated from disease and death. Transhumanists hope for a posthumanity as the next stage of human evolution, preserving at the same time the Enlightenment focus on science and reason. Transhumanism can be seen as an ideology that aims for a realisation of religious narratives and promises by technological means.

The intellectual currents sketched out above are fuelled by a multitude of technoscientific and social developments that challenge notions of the human as well as traditional understandings of the boundaries between the body and technology. Such developments include, but are not limited to, monitoring and tracking technologies, new means of sensory substitution and enhancement, and a wide range of biosignal-based technologies. Many of the discussions about these developments are focusing on current or future options for human enhancement, often on the basis of the ideology of liberalism and individual choice. The malleability of human corporeality provides space for human creativity and ambitions, but this culture of experimentation with the human body is closely linked to military and other political goals.

In this special section, we would like to draw attention to the varied spectrum of cultural and very personal practices of experimentation with the human body that often take place outside the confines of institutionalised technoscience. Sometimes labelled 'sciencefictionesque', these practices, which are frequently conducted by amateurs, constitute societal experiments with the potentials of new and emerging technology. Known, for example, as 'body hackers', 'grinders' or 'self-made cyborgs' and engaging in unusual forms of body modification, these practitioners are enthusiasts who do not necessarily have any 'disability' in the conventional sense of the term. Many of them conform to the sociomedical body norms of Western societies. These new cyborgs aim to acquire new sensory capabilities that allow them to undergo corporeal experiences previously unavailable to humans. They consider the body a highly malleable material, a transformable, improvable, augmentable entity. This attitude towards human corporeality corresponds to certain trends in performance art. The new forms of embodiment are based on the deployment of novel and often highly advanced technologies. In some cases, body modification practices of this kind are accompanied by futuristic visions of a technologically transformed human body reminiscent of the imaginaries found in cyberpunk culture.

Body hacking is an activity that occurs at the intersections of technoscience, sociocultural activism and the 
human body. It urges us to interrogate the role played by technology in society and our understandings of what it means to be human. Many controversies may be, or actually are, provoked by these practices: the notion of the body as an entity whose integrity must be protected, for example, is called fundamentally into question. Moreover, there is a tendency to accept 'cyborg technologies' only if they help disabled persons to fulfil a cultural norm, and many ethical discussions revolve around the questionable distinction between therapy and enhancement. Referring to Continental European philosophy, we might distinguish between the body that one 'has' and the body that one 'is', a distinction that raises a host of fascinating questions about 'cyborg bodies'. Against this multi-faceted background, the collection of papers in this special section encompasses first-hand accounts of cyborg practices as well as intellectual reflections on their implications.

Kevin Warwick, a pioneer of cyborgism, provides the reader with an overview on his own and other experiments with cyborg technologies, commenting on them in the light of the new cyborgism movement, which is taking the relevant technologies and experiments out of the laboratory. Bárbara N. Duarte discusses the subculture of cyborgism and its goal of merging humans with technology. Adapting Haraway's term 'entangled agencies', she aims to shed light on the contours of the new homo faber, a being that not only transforms non-human nature and performs medical practices, but also deliberately changes its own corporeality without therapeutic goals. Lisette Olivares, a researcher and body hacker, describes experiments with the human body conducted or planned by the performance artist Cheto Castellano and herself. Referring to Eva Hayward's concept of 'transbecoming', she gives an account of the speculative feminist cyborg project ' 10,000 Generations Later', which has sought to challenge concepts such as gender or race. Stefan Greiner describes his experiences with sensory enhancement by means of subdermal magnets. According to Greiner, the body has no clear boundaries, and humans should best be understood as interfaces in a metanatural/cultural network. He also points to societal aspects of the new cyborgism. In his paper, the deaf
Enno Park describes his own experiences with a cochlear implant and argues against the notion of the 'repair' of disabilities: in his view, most disabilities are far too complex to be 'repaired', and the very idea of 'repairing' deviations from body norms runs counter to the values of human diversity and social inclusion. In Park's opinion, enhancement technologies can at the same time be deemed potential means of emancipation, in particular when it comes to humans' interaction with their environment. However, we also need to reflect on the very notion of 'human enhancement'. Stefanie Rembold accordingly argues that the term 'enhancement' should be culturally contextualised. After surveying the history of human body modification, she recommends the use of the term 'body modification'.

Given the developments summarised above, there are good reasons to believe we are currently witnessing a process with the potential to bring about a massive transformation of human corporeality. The questions this throws up about the future(s) of gender, race, society, diversity and inclusion, and the definition of humanity are no longer science-fictionesque thought experiments. Cyborg technologies have become crucial elements of our way of being in the world, and reflection on these technologies can potentially illuminate the interrelations between nature, the human body and technology more generally, both in Western societies and beyond. We therefore hope this special section will help inspire a broad discourse on cyborgism, this new dance of encounters between body, technology and society.

\section{References}

1. Latour B (2005) Reassembling the social: an introduction to actor-network-theory. Oxford University Press, New York

2. Haraway DJ (2008) When species meet. University of Minnesota Press, Minneapolis

3. Hayles K (1999) How we became posthuman: virtual bodies in cybernetics, literature and informatics. University of Chicago Press, Chicago

4. Clark A (2003) Natural-born cyborgs: minds, technologies, and the future of human intelligence. Oxford University Press, New York 